\title{
Review on the Antimicrobial Resistance of Pathogens from Tracheal and Endotracheal Aspirates of Patients with Clinical Manifestations of Pneumonia in Bacolod City in 2013
}

\author{
Alain C. Juayang, Dominador G. Maestral Jr., Gemma B. de los Reyes, \\ Michael Angelo D. Acosido, and Christine T. Gallega \\ Medical Technology Program, College of Arts, Sciences and Education, Colegio San Agustin-Bacolod, 6100 Bacolod City, Philippines \\ Correspondence should be addressed to Alain C. Juayang; maigeck@yahoo.com
}

Received 6 September 2014; Revised 14 January 2015; Accepted 19 January 2015

Academic Editor: Rodrigo E. Mendes

Copyright (C) 2015 Alain C. Juayang et al. This is an open access article distributed under the Creative Commons Attribution License, which permits unrestricted use, distribution, and reproduction in any medium, provided the original work is properly cited.

\begin{abstract}
Microbiological content specifically bacterial and fungal etiologies from tracheal aspirates in a tertiary hospital in Bacolod City was reviewed for baseline information. A total of 130 tracheal aspirates were subjected for culture to isolate and identify the pathogen and determine their susceptibilities to various antibiotics. Productions of certain enzymes responsible for antibiotic resistance like ESBL (Extended Spectrum Beta-Lactamase), metallo- $\beta$-lactamase, and carbapenemase were also studied. Out of 130 specimens, $69.23 \%$ were found to be positive for the presence of microorganisms. Most infections were from male patients aging 60 years and above, confined at the Intensive Care Units (ICU). Pseudomonas aeruginosa and Klebsiella pneumoniae were found to be the most frequent bacterial isolates and non-Candida albicans for fungal isolates, respectively. Among the various antibiotics tested, most isolates were found to be resistant to third generation cephalosporins and penicillins, but susceptible to aminoglycoside Amikacin. On the other hand, production of ESBL and carbapenemase was found to be common among members of Enterobacteriaceae especially K. pneumoniae.
\end{abstract}

\section{Introduction}

Endotracheal specimens or tracheal aspirates are usually done quantitatively in culture in order to determine the presence of pneumonia in ventilated patients admitted in most hospitals rather than bronchoalveolar lavage (BAL) or protected specimen brush (PSB) and are considered as reliable alternative compared to the latter specimens [1-3]. These specimens are often used in the diagnosis of pneumonia, including ventilator acquired pneumonia. In the hospital, tracheal aspiration for the diagnosis of nosocomial infection is also common in patients admitted in the ICU [4-6].

Several organisms are accounted for causing pneumonia. Common causative agents are that of Pseudomonas species, Acinetobacter species, Staphylococcus aureus, and Enterobacteriaceae including the endogenous bacteria [7-11]. The common problem however as noted in other studies is that bacterial pathogens from tracheal aspirates tend to be of a multidrug-resistant type [8-10]. Antibiotic treatment using piperacillin-tazobactam has shown efficacy in lowering hospital mortality rate [12], so as with fluoroquinolones, Amikacin, and carbapenems [8].

Although many foreign studies had investigated the microbiological content of tracheal and endotracheal aspirates, it is also worthwhile that locally gathered data will be given the same importance $[13,14]$. These lead to the aim of the study to determine and enumerate the presence of pathogens and its antibiotic susceptibility pattern in endotracheal and tracheal aspirates from a tertiary hospital in Bacolod City, Philippines, for the year 2013 for baseline information.

\section{Materials and Methods}

2.1. Inclusion and Exclusion Criteria. This study was conducted from January 2013 to December 2013 in a Tertiary 
Hospital in Bacolod City, Philippines, and was patterned on the study of Khosravi et al. in 2013 [10]. Samples were derived from both admitted and outpatients who underwent intubation or tracheostomy procedure due to impaired respiratory or pulmonary functions like those who suffered severe COPD, acute asthma attack, and upper airway obstruction, those who fell in the GCS 7 and below, and so forth having manifestations of pneumonia as assessed by their attending physicians. These patients were then grouped according to whether they were outpatients, non-ICU patients, or ICU patients. These groups were then categorized according to age and gender. Specimens were collected by the attending physicians and were sent to the laboratory for microbial analyses. Samples with pus cells of more than 25/LPF were included in the study, whereas those with less than 25/LPF pus cells were excluded [3]. The study also considered microbial growth of $10^{4} \mathrm{CFU} / \mathrm{mL}$ or more for diagnostic threshold $[2,3]$.

2.2. Isolation and Identification of Pathogens. Submitted samples were then inoculated on Sheep's Blood Agar, Mac Conkey, and Chocolate Agar for routine bacterial and yeast isolation. Traditional and automated methods were employed in identifying the organisms based on their reaction in biochemical tests using both schemes in identifying species of Enterobacteriaceae and Pseudomonas aeruginosa [15]. Identification of fungal isolates was based on the study of Ogba et al. [16].

2.3. Antimicrobial Susceptibility Testing. Antimicrobial susceptibility testing was performed by Kirby-Bauer disc diffusion method strictly adhering to the standards stipulated in the M02-A11 [17] and M100-S23 of CLSI [18]. Inoculums were prepared using direct colony suspension and adjusted to that of $0.5 \mathrm{McF}$ arland Standard solutions. A sterile swab was then immersed into the inoculum and swabbed on Mueller Hinton Agar II (MH) plates and allowed to dry for 5-15 minutes. The antibiotic discs were then placed 2 centimeters apart from each other. The plates were then incubated at $35-37^{\circ} \mathrm{C}$ for 18 to 24 hours and zone of inhibitions was measured with the use of Vernier caliper. The results were sequentially interpreted based on the guidelines stipulated in the M100-S23 standards [18].

Antibiotics that were used include Amikacin $(30 \mu \mathrm{g})$, Ampicillin-Sulbactam $(10 / 10 \mu \mathrm{g})$, Aztreonam $(30 \mu \mathrm{g})$, CoAmoxiclav $(20 / 10 \mu \mathrm{g})$, Cefepime $(30 \mu \mathrm{g})$, Cefoxitin $(30 \mu \mathrm{g})$, Cefotaxime $(30 \mu \mathrm{g})$, Ceftriaxone $(30 \mu \mathrm{g})$, Ceftazidime $(30 \mu \mathrm{g})$, Cefuroxime (30 $\mu \mathrm{g})$, Chloramphenicol $(30 \mu \mathrm{g})$, Sulfamethoxazole-Trimethoprim $(1.25 / 23.75 \mu \mathrm{g})$, Ertapenem $(10 \mu \mathrm{g})$, Gentamycin $(10 \mu \mathrm{g})$, Imipenem $(10 \mu \mathrm{g})$, Meropenem $(10 \mu \mathrm{g})$, Tazo.Piperacillin $(100 / 10 \mu \mathrm{g})$, Tetracycline $(30 \mu \mathrm{g})$, Tobramycin $(10 \mu \mathrm{g})$, and Fluconazole $(20 \mu \mathrm{g})$. The data were encoded and analyzed using the WHONET version 5.6 downloaded from WHO website.

2.4. Detection of Extended Spectrum Beta-Lactamase. Screening and confirmatory tests for Extended Spectrum BetaLactamase (ESBL) were determined using the antibiotic discs Ceftazidime (30 $\mu \mathrm{g})$, Aztreonam (30 $\mu \mathrm{g})$, Cefotaxime (30 $\mu \mathrm{g})$,
Ceftriaxone $(30 \mu \mathrm{g})$, Cefotaxime-clavulanic acid $(30 / 10 \mu \mathrm{g})$, and Ceftazidime-clavulanic acid $(30 / 10 \mu \mathrm{g})$ as mentioned in the M100-S23 [18]. For screening of ESBL, any isolate with a zone on Ceftazidime of $\leq 22 \mathrm{~mm}$, Aztreonam- $\leq 27 \mathrm{~mm}$, Cefotaxime $-\leq 27 \mathrm{~mm}$, and Ceftriaxone $<25 \mathrm{~mm}$ may indicate enzyme production. Isolates that fell in the aforementioned screening criteria were then phenotypically confirmed using disc potentiation assay utilizing Ceftazidime, Cefotaxime, Cefotaxime-clavulanate discs, and Ceftazidimeclavulanate discs. A $\geq 5 \mathrm{~mm}$ increase in zone diameter of either antimicrobial agent tested in combination with clavulanate versus the zone diameter of the agent when tested alone confers ESBL.

\subsection{Detection of Metallo-Beta-Lactamase and Carbapenemase} Production among Isolates. Determination of metallo- $\beta$ lactamase and carbapenemase was done in Pseudomonas and Acinetobacter isolates that were found to be resistant to the tested carbapenem using the Imipenem-EDTA synergistic test as mentioned in the study of Pitout et al. [19]. Modified Hodge Test was also used to the isolates of Enterobacteriaceae that were found to be resistant to any of the carbapenems based on the guidelines of CLSI [18].

2.5.1. Combined Disk Test Using Imipenem and EDTA. This assay was based on the method mentioned in the study of Pitout et al. [19], wherein a $0.5 \mathrm{McF}$ arland standardized inoculum of the test isolate was inoculated onto a $\mathrm{MH}$ agar. Two $10 \mu \mathrm{g}$ imipenem discs were initially placed onto the agar and $10 \mu \mathrm{L}$ of $930 \mu \mathrm{g}$ of EDTA solution is added to one of the imipenem disc. An isolate with a $\geq 7 \mathrm{~mm}$ difference in the zone of inhibition between Imipenem-EDTA disc and Imipenem disc is considered as an MBL-producer.

2.5.2. Modified Hodge Test. Confirmatory Test for Suspected Carbapenemase Production or the Modified Hodge Test was done by preparing a $0.5 \mathrm{McF}$ arland Standard suspension by direct colony suspension of E. coli ATCC 25922 in saline and diluted 1:10 in saline based on the methods described in M100-S23 [18]. The MH plate was inoculated in the same manner of routine disc diffusion. The plate was then allowed to dry for 3 to 10 minutes. Ertapenem disc $(10 \mu \mathrm{g})$ or Meropenem $(10 \mu \mathrm{g})$ was then placed on the center of the plate. Three to five colonies were picked by using a loop or a swab of test or QC (ATCC BAA 1706 and ATCC BAA 1705) organism grown overnight on a blood agar plate and was streaked on a straight line out from the edge of the disc. Following 16-24 hours of mesothermic incubation, carbapenemase production is seen with an enhanced growth of $E$. coli wherein carbapenemase produced by the isolate or QC organism ATCC BAA 1705 inactivated either antibiotic Meropenem or Ertapenem that diffused to the media, while negative results showed no enhanced growth of $E$. coli.

2.6. Quality Control. Reference strains that were used in this study include $S$. aureus ATCC 25923, E. coli ATCC 25922, E. coli 35218 P. aeruginosa ATCC 27853, and K. pneumoniae ATCC BAA 1705 and 1706. 


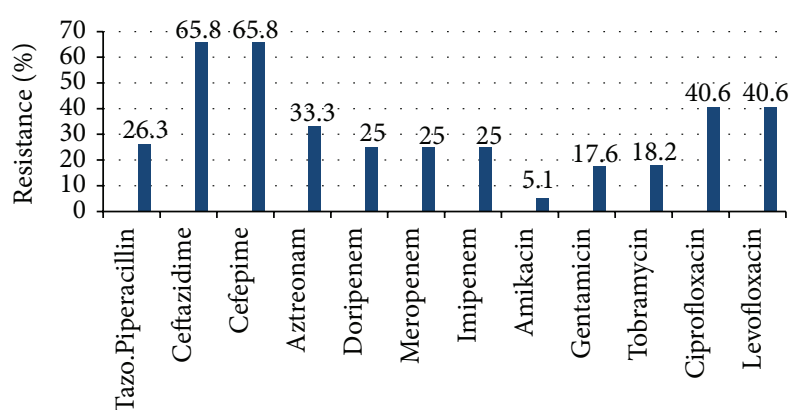

Figure 1: Antibiotic resistance of the isolated $P$. aeruginosa against various antibiotics.

\section{Results}

3.1. Isolated Pathogens. Out of 130 specimens submitted, 90 specimens were found to be positive in cultures with 96 isolates. Most of the positive samples came from patients aged 60 years old and above encompassing a total of $87.77 \%$ and are mostly males $(65.55 \%)$. Also, $7.79 \%$ of the samples came from aged 30-59 years, while $4.44 \%$ came from pediatric patients. Most of the samples were from ICU (62.5\%), Private Rooms (18.75\%), Wards (9.38\%), Outpatients (4.93\%), and NICU/PICU (4.44\%). Based on the microbiological data collected, $P$. aeruginosa was the prevailing bacteria with $41.66 \%$. The number and frequency of other microbes were K. pneumoniae (16.67\%), Enterobacter gergoviae (6.25\%), non-Candida albicans (7.29\%), Enterobacter aerogenes and Burkholderia cepacia (5.2\%), Enterobacter cloacae and Escherichia coli (4.17\%), A. baumannii (3.12\%), Candida albicans and Citrobacter koseri (2.08\%), and Serratia marcescens (1.04\%).

3.2. Antimicrobial Susceptibility. Antimicrobial susceptibility also revealed that $P$. aeruginosa has the highest resistance against Cefepime and Ceftazidime with 65.8\% (CI 48.6$79.9 \%)$, followed by Ciprofloxacin and Levofloxacin with 40.6\% (CI 24.2-59.2), and Amikacin with 5.1\% (CI 0.9-18.6) as the lowest, as reflected in Figure 1. On the other hand, Enterobacteriaceae have the most resistance against ampicillin with $96.9 \%$ (CI 82.0-99.8\%), cefuroxime with $82.1 \%$ (CI 62.4-93.2), and ampicillin-sulbactam $81.8 \%$ (CI 63.9-92.4) but with least resistance to Amikacin with 9.7\% (CI 2.5$26.9 \%$ ) followed by carbapenems Ertapenem, Imipenem, and Meropenem with 15.2\% (CI 5.7-32.7). The data for the susceptibility of Enterobacteriaceae is shown in Figure 2.

Antibiotic susceptibility pattern of B. cepacia, A. baumannii, and Candida species was not included due to the fact that they did not meet the minimum number of 30 isolates as per recommendation in the M39-A4 manual [20]. However, it is interesting to note that 2 out of 3 isolates of $A$. baumannii were pan-resistant to all tested antibiotics, 2 out of 9 Candida species were resistant to fluconazole, and all $B$. cepacia were sensitive to the tested antibiotics. Additionally, among the $40 P$. aeruginosa isolates, $25 \%$ were resistant to carbapenems, Imipenem, and Meropenem, yet none of the $25 \%$ were positive for metallo- $\beta$-lactamase production by Imipenem-EDTA synergistic test. Moreover, out of 39 Enterobacteriaceae, $78.3 \%$

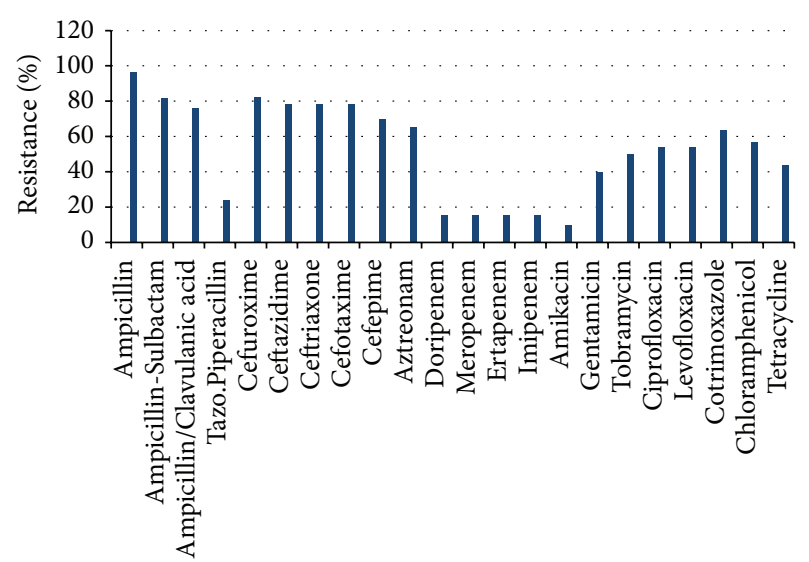

FIgURE 2: Antibiotic resistance of the isolated Enterobacteriaceae against various antibiotics.

were Extended Spectrum $\beta$-Lactamase (ESBL) producing and $10.26 \%$ were carbapenemase producing isolates.

\section{Discussions}

Out of 130 samples submitted for microbial culture 90 $(69.23 \%)$ were found positive for microbial growth. This finding is most likely due to the reason that endotracheal tubes alter host defenses, impair mechanical clearance, and can cause trauma or inflammation [21]. The majority of the patients subjected to tracheal aspirates are mostly male and age 65 years of age. It was also noted that majority of the patients were admitted in the ICU since these patients were critically ill and have the most chance of acquiring health care acquired infections [11]. Colonization is a matter of concern because admissions on the said units are patients that are critically ill due to their immunological status or age [10]. This finding was also at par with the findings of Khosravi et al. [10].

The isolated bacteria in this study are often the causative agents of lower respiratory health care related infections, as mentioned by Craven and Hjalmarson [7], Resende et al. [5], and Vanhems et al. [6]. P. aeruginosa is rarely found as a part of the microbial flora of healthy populace, but it was noted for its liking for moist environment like aqueous solutions used in medical care and becomes potentially problematic in the hospital environment [22, 23]. Furthermore, P. aeruginosa can also be present in some objects like aerators, sinks, respiratory equipment, and any other water sources [23]. It can also colonize gastrointestinal tract and moist body sites. Together with Acinetobacter species, these bacteria can be passed from person to person or environmental contamination [22]. Moreover, bacteria like K. pneumoniae, E. coli, and $S$. marcescens can be present in urinary catheters, equipment, and other contaminated fluids that can survive in inanimate surfaces for months $[23,24]$ and can even live longer compared to gram positive bacteria. The above findings are comparable to the study of Khosravi et al. [10] and Resende et al. [5] (2013), but in contrast to the data of Vanhems et al. [6] where $P$. aeruginosa was reported to be infrequent. The study of Jakribettu and Boloor [8] also showed similar series 
of pathogens but $K$. pneumoniae was found to be the most isolated pathogen (34\%) rather than P. aeruginosa (20\%). As a subject of concern, $P$. aeruginosa and Acinetobacter species have higher rate of pulmonary recurrence suggesting that longer courses of therapy are needed [12].

Frequency of multidrug resistance is highly emphasized in this study. Current data reveals that most bacteria such as Enterobacteriaceae and $P$. aeruginosa were least resistant to Amikacin with $9.7 \%$ and $5.1 \%$, respectively. Alternately, Enterobacteriaceae had the most resistance to ampicillin followed by cefuroxime which conforms with the data of Jakribettu and Boloor [8], and with Khanal et al. [9]. Even though Amikacin was found to be the antibiotic with the least resistance against Enterobacteriaceae and $P$. aeruginosa, this antibiotic however is known to cause a series of side effects including nephrotoxicity [25], Fanconi-like or Bartter-like syndrome, and hearing loss [26] making any of the carbapenems [27] and Piperacillin/Tazobactam still worth to be one of the most effective drugs for treatment as of this time. As with this study, it was also observed that $78.3 \%$ of the isolates were found to be resistant to third generation cephalosporins and $58 \%$ to fluoroquinolones, respectively.

The presence of multidrug resistant bacteria specifically ESBL and carbapenemase producing Enterobacteriaceae and carbapenem-resistant $P$. aeruginosa are of great threats noting that carbapenem is still considered as the last resort in treating multidrug resistant [28] bacteria. The number of ESBL confirmed by double disc synergistic test also corresponds to the number of isolates that were resistant to third generation cephalosporins, given that susceptibility to these drugs is also accounted for the screening of ESBL in M100-S23 guidelines of CLSI [18]. It is also worthwhile to mention that these bacteria are capable of causing an outbreak in hospital setting especially in the ICU $[22,28,29]$. These organisms can also persist in the environment for months and can be transmissible as nosocomial pathogens as suggested in the study of Kramer et al. in 2006 [24]. Sydnor and Perl [23] also demonstrated that infections with MDR bacteria like ESBL mean increase in length of hospital stay, increase in hospital charges, and increase in mortality rate. Also included in the list are carbapenemase producing organisms which are considered notorious and alarming for its developing resistance to almost all currently available antibiotics, not mentioning its gene (NDM-1) present on its plasmid that is easily transferrable to other organisms.

Overall, this study presents substantiation and without much difference with other literatures about the microbial content of tracheal aspirates and their resistance to the various antibiotics.

\section{Conclusions}

The data generated by this study conclude that the most common pathogens isolated in tracheal and endotracheal aspirates are $P$. aeruginosa and members of the family Enterobacteriaceae such as K. pneumoniae, E. coli, and Enterobacter spp. which are most susceptible to Amikacin. Production of ESBL among Enterobacteriaceae was evident so as their resistance to carbapenems. Though resistance to carbapenems was $15.2 \%$, the actual carbapenemase producing Enterobacteriaceae from these isolates was $10.26 \%$.

\section{Conflict of Interests}

The authors declare no conflict of interests.

\section{References}

[1] D. C. J. Bergmans, M. J. M. Bonten, P. W. de Leeuw, and E. E. Stobberingh, "Reproducibility of quantitative cultures of endotracheal aspirates from mechanically ventilated patients," Journal of Clinical Microbiology, vol. 35, no. 3, pp. 796-798, 1997.

[2] A. A. El Solh, M. E. Akinnusi, L. A. Pineda, and C. R. Mankowski, "Diagnostic yield of quantitative endotracheal aspirates in patients with severe nursing home-acquired pneumonia," Critical Care, vol. 11, article R57, 2007.

[3] M. Ioanas, R. Ferrer, J. Angrill, M. Ferrer, and A. Torres, "Microbial investigation in ventilator-associated pneumonia," European Respiratory Journal, vol. 17, no. 4, pp. 791-801, 2001.

[4] M. Klompas, M. Kulldorff, and R. Platt, "Risk of misleading ventilator-associated pneumonia rates with use of standard clinical and microbiological criteria," Clinical Infectious Diseases, vol. 46, no. 9, pp. 1443-1446, 2008.

[5] M. M. Resende, S. G. Monteiro, B. Callegari, P. M. S. Figueiredo, C. R. A. V. Monteiro, and V. Monteiro-Neto, "Epidemiology and outcomes of ventilator-associated pneumonia in northern Brazil: an analytical descriptive prospective cohort study," BMC Infectious Diseases, vol. 13, no. 1, article 119, 2013.

[6] P. Vanhems, T. Bénet, N. Voirin et al., "Early-onset ventilatorassociated pneumonia incidence in intensive care units: a surveillance-based study," BMC Infectious Diseases, vol. 11, no. 1, article 236, 2011.

[7] D. E. Craven and K. I. Hjalmarson, "Ventilator-associated tracheobronchitis and pneumonia: thinking outside the Box," Clinical Infectious Diseases, vol. 51, supplement 1, pp. S59-S66, 2010.

[8] R. P. Jakribettu and R. Boloor, "Characterisation of aerobic bacteria isolated from endotracheal aspirate in adult patients suspected ventilator associated pneumonia in a tertiary care center in Mangalore," Saudi Journal of Anaesthesia, vol. 6, no. 2, pp. 115-119, 2012.

[9] S. Khanal, D. Joshi, D. Bhatta, U. Devkota, and B. Pokhrel, “ $\beta$ lactamase-producing multidrug-resistant bacterial pathogens from tracheal aspirates of intensive care unit patients at national institute of neurological and allied sciences, Nepal," ISRN Microbiology, vol. 2013, Article ID 847569, 5 pages, 2013.

[10] A. D. Khosravi, N. Parhizgari, E. A. Montazeri, A. Mozaffari, and F. Abbasi, "The prevalence of bacteria isolated from endotracheal tubes of patients in golestan hospital, Ahvaz, Iran, and determination of their antibiotic susceptibility patterns," Jundishapur Journal of Microbiology, vol. 6, no. 1, pp. 67-71, 2013.

[11] S. M. Koenig and J. D. Truwit, "Ventilator-associated pneumonia: diagnosis, treatment, and prevention," Clinical Microbiology Reviews, vol. 19, no. 4, pp. 637-657, 2006.

[12] C. Rotstein, G. Evans, A. Born et al., "Clinical practice guidelines for hospital-acquired pneumonia and ventilator associated pneumonia in adults," Canadian Journal of Infectious Diseases and Medical Microbiology, vol. 19, no. 1, pp. 19-53, 2008. 
[13] J. Swanson and D. Wells, "Emperical antibiotic therapy for ventilator-associated pneumonia," Antibiotics, vol. 2, no. 3, pp. 339-351, 2013.

[14] A. Torres, M. Ferrer, and J. R. Badia, "Treatment guidelines and outcomes of Hospital-acquired and ventilator-associated pneumonia," Clinical Infectious Diseases, vol. 51, no. S1, pp. S48S53, 2010.

[15] J. J. Farmer III, B. R. Davis, F. W. Hickman-Brenner et al., "Biochemical identification of new species and biogroups of Enterobacteriaceae isolated from clinical specimens," Journal of Clinical Microbiology, vol. 21, no. 1, pp. 46-76, 1985.

[16] O. Ogba, L. Abia-Bassey, J. Epoke, B. Mandor, and G. Iwatt, "Characterization of Candida species isolated from cases of lower respiratory tract infection among HIV/AIDS patients in Calabar, Nigeria," World Journal of AIDS, vol. 3, no. 3, pp. 201206, 2013.

[17] Clinical and Laboratory Standard Institute, Performance Standards for Antimicrobial Disc Susceptibility Tests: Approved Standard, M02-A11, Wayne, Pa, USA, Clinical and Laboratory Standards Institute, 2011.

[18] Clinical and Laboratory Standard Institute, "Performance standards for antimicrobial disk susceptibility tests," Approved Standard Document M100-S23, Clinical and Laboratory Standards Institute, Wayne, Pa, USA, 2013.

[19] J. D. D. Pitout, D. B. Gregson, L. Poirel, J.-A. McClure, P. Le, and D. L. Church, "Detection of Pseudomonas aeruginosa producing metallo- $\beta$-lactamases in a large centralized laboratory," Journal of Clinical Microbiology, vol. 43, no. 7, pp. 3129-3135, 2005.

[20] Clinical and Laboratory Standards Institute, Analysis and Presentation of Cumulative Antimicrobial Susceptibility Test Data: Approved Guideline, Clinical and Laboratory Standards Institute, Wayne, NJ, USA, 4th edition, 2014.

[21] E. Alp and A. Voss, "Ventilator associated pneumonia and infection control," Annals of Clinical Microbiology and Antimicrobials, vol. 5, article 7, 2006.

[22] D. L. Paterson, "The epidemiological profile of infections with multidrug-resistant Pseudomonas aeruginosa and Acinetobacter species," Clinical Infectious Diseases, vol. 43, supplement 2, pp. S43-S48, 2006.

[23] E. R. M. Sydnor and T. M. Perl, "Hospital epidemiology and infection control in acute-care settings," Clinical Microbiology Reviews, vol. 24, no. 1, pp. 141-173, 2011.

[24] A. Kramer, I. Schwebke, and G. Kampf, "How long do nosocomial pathogens persist on inanimate surfaces? A systematic review," BMC Infectious Diseases, vol. 6, article 130, 2006.

[25] M. A. Sanz, J. López, J. J. Lahuerta et al., "Cefepime plus amikacin versus piperacillin-tazobactam plus amikacin for initial antibiotic therapy in haematology patients with febrile neutropenia: results of an open, randomized, multicentre trial," Journal of Antimicrobial Chemotherapy, vol. 50, no. 1, pp. 79-88, 2002.

[26] A. Chrispal, H. Boorugu, A. T. Prabhakar, and V. Moses, "Amikacin-induced type 5 Bartter-like syndrome with severe hypocalcemia," Journal of Postgraduate Medicine, vol. 55, no. 3 , pp. 208-210, 2009.

[27] M.-A. W. Aarts, J. N. Hancock, D. Heyland, R. S. McLeod, and J. C. Marshall, "Empiric antibiotic therapy for suspected ventilator-associated pneumonia: a systematic review and meta-analysis of randomized trials," Critical Care Medicine, vol. 36, no. 1, pp. 108-117, 2008.

[28] M. J. Schwaber, S. Klarfeld-Lidji, S. Navon-Venezia, D. Schwartz, A. Leavitt, and Y. Carmeli, "Predictors of carbapenem-resistant
Klebsiella pneumoniae acquisition anions hospitalized adults and effect of acquisition on mortality," Antimicrobial Agents and Chemotherapy, vol. 52, no. 3, pp. 1028-1033, 2008.

[29] S. Hadzic, A. Custovic, J. Smajovic, and S. Ahmetagic, "Distribution of nosocomial infections caused by Klebsiella pneumoniae ESBL strain," Journal of Environmental and Occupational Science, vol. 1, no. 3, pp. 141-146, 2012. 

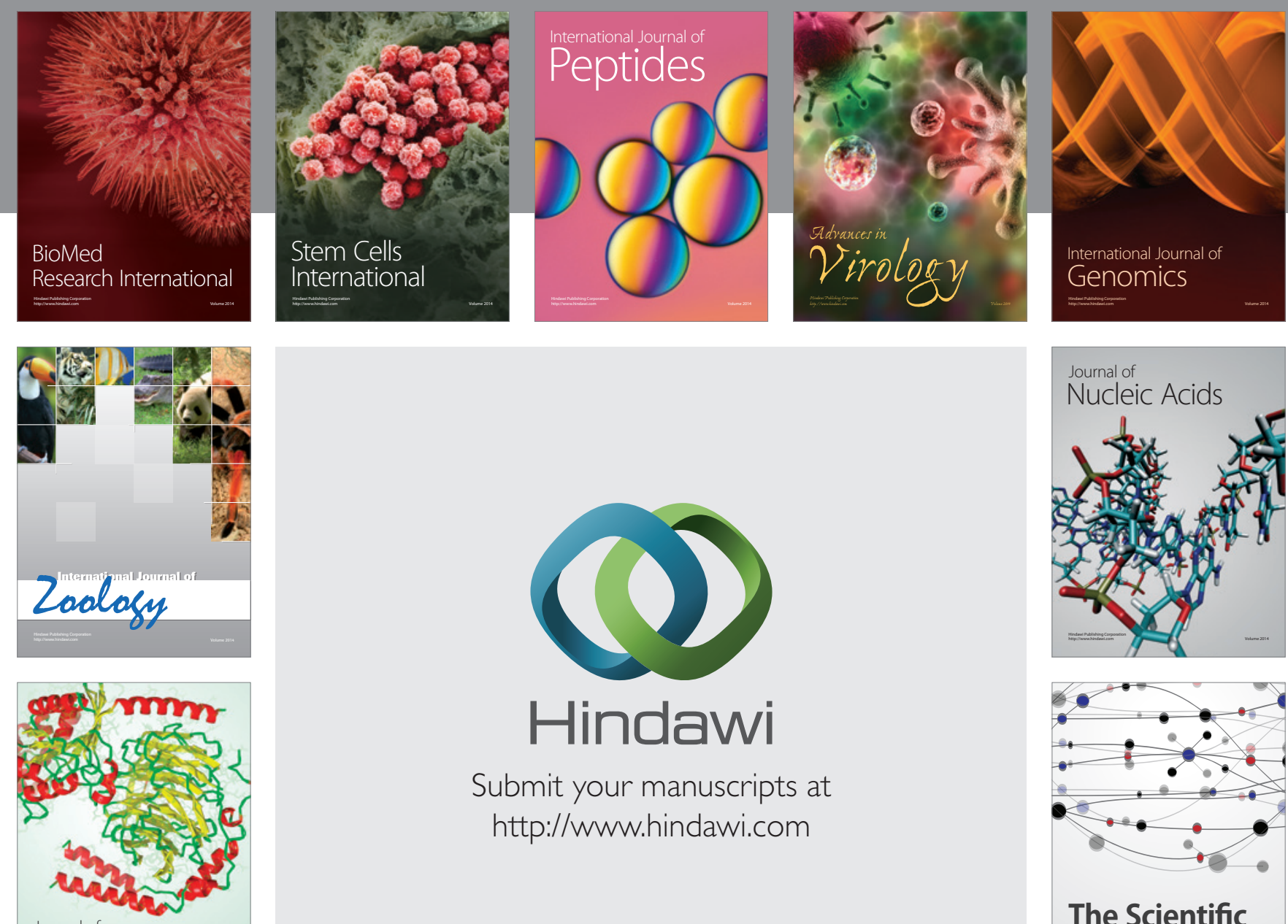

Submit your manuscripts at

http://www.hindawi.com

Journal of
Signal Transduction
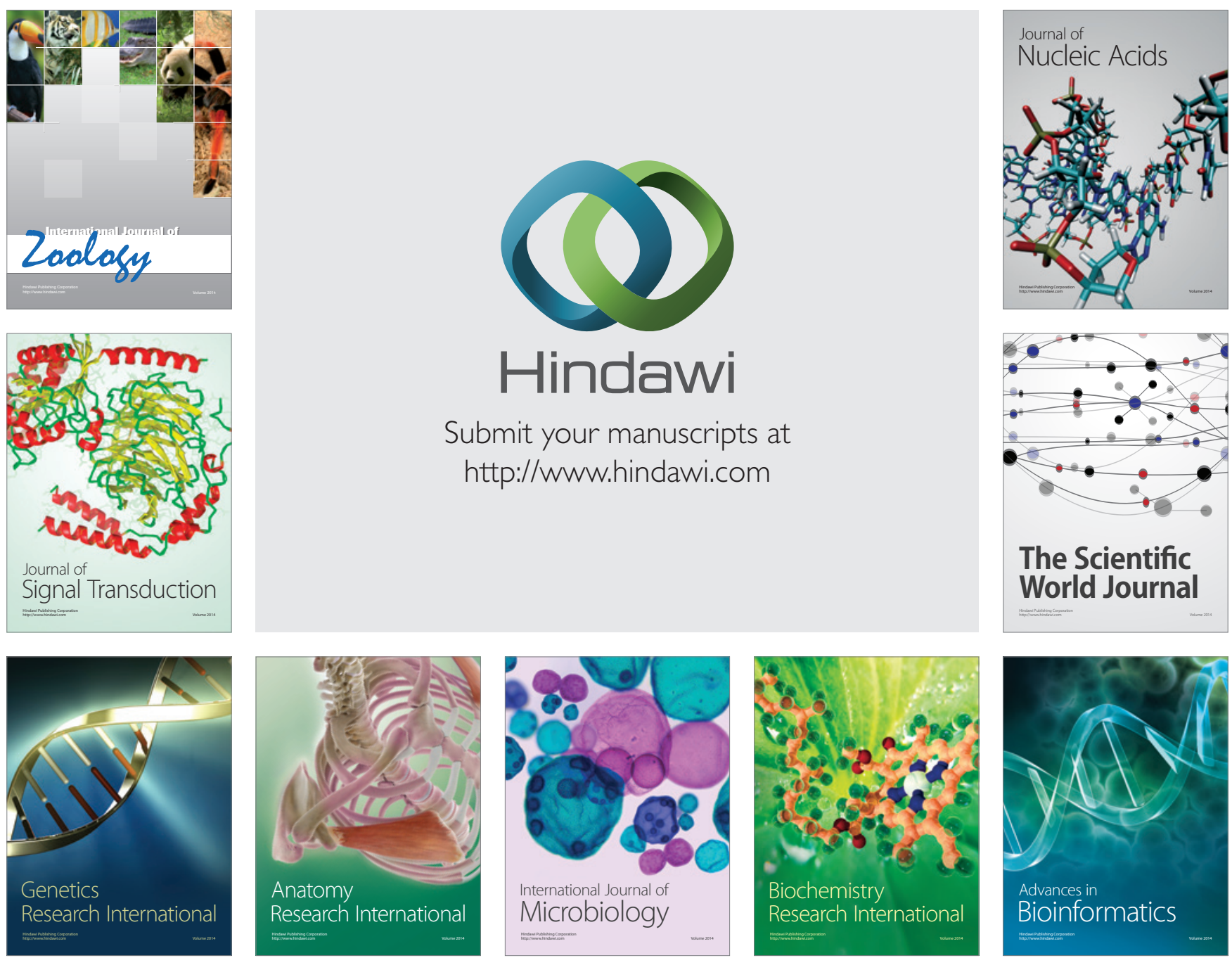

The Scientific World Journal
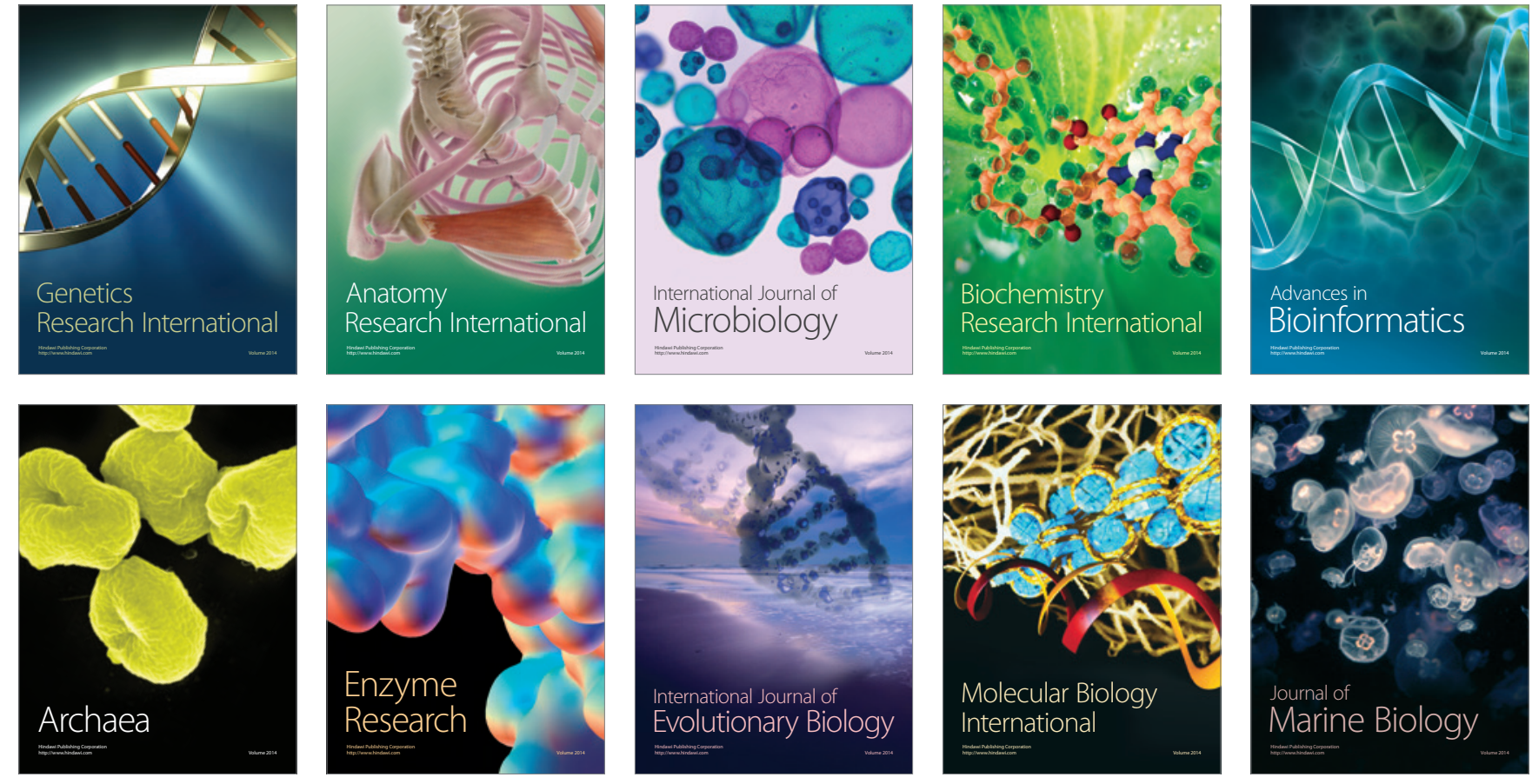